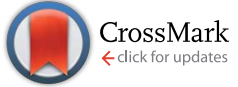

Cite this: RSC Adv., 2017, 7, 3229

Received 18th October 2016

Accepted 17th December 2016

DOI: $10.1039 / c 6 r a 25403 a$

www.rsc.org/advances

\section{Influence of steric demand on ruthenium-catalyzed cycloaddition of sterically hindered azides $\uparrow$}

\author{
Venkata S. Sadu, ${ }^{a}$ Sirisha Sadu, ${ }^{a}$ Seji Kim, ${ }^{\text {I }}$ In-Taek Hwang, ${ }^{\text {' Ki-Jeong Kong }}$ \\ and Kee-In Lee*ab
}

The RuAAC of sterically hindered 2,2-diaryl-2-azidoamines and terminal alkynes resulted in the unprecedented formation of 1,4-disubstituted-1,2,3-triazoles. A control experiment with 2-(azidomethyl) pyrrolidine revealed the usual selectivity with RUAAC and the reactions of azides with intermediate bulkiness gave mixtures of 1,4- and 1,5-regioisomers. The results suggest that the steric demands could annul the preference and influence on the regioselectivity of RuAAC substantially.
The Huisgen 1,3-dipolar cycloaddition between azides and alkynes is the most convenient way to access 1,2,3-triazoles, but it produces a mixture of 1,4- and 1,5-disubstituted triazoles and may require elevated temperatures. ${ }^{1}$ After the discovery of copper-catalyzed azide-alkyne cycloaddition (CuAAC) leading to the regioselective formation of 1,4-disubstituted 1,2,3-triazoles, ${ }^{2}$ the reaction enabled the rapid spread of triazole chemistry across multilateral disciplines including medicinal chemistry, chemical biology and material sciences due to its high degree of reliability, specificity and biocompatibility. ${ }^{3}$ In addition, recent advances in ruthenium-catalyzed azide-alkyne cycloaddition (RuAAC) allow entry to 1,5-regioisomers as the complementary version to the copper catalysis. Among them, ruthenium complexes containing the pentamethylcyclopentadienyl ligand $\left(\mathrm{Cp}^{*}\right)$ are the most prominent class of catalysts showing high levels of regioselectivity for a broad substrate scope. ${ }^{4}$ Particularly interesting are approaches featuring the complementary pairings between CuAAC and RuAAC to the same substrates as illustrated in

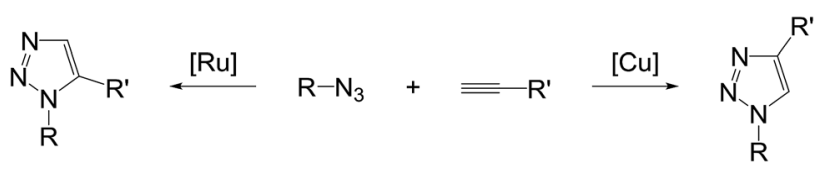

Scheme 1 Schematic drawing of the complementarity between CUAAC and RuAAC.

\footnotetext{
${ }^{a}$ Major of Green Chemistry and Environmental Biotechnology, University of Science \& Technology, Taejon 305-350, Korea. E-mail: kilee@krict.re.kr

${ }^{b}$ Green Chemistry Division, Korea Research Institute of Chemical Technology, Taejon 305-600, Korea

$\dagger$ Electronic supplementary information (ESI) available. CCDC 1503841 X-ray crystallographic data of $\mathbf{2 b}$ have been deposited in the Cambridge Crystallographic Data Centre database with accession number. For ESI and crystallographic data in CIF or other electronic format see DOI: 10.1039/c6ra25403a
}

Scheme 1, so that the pairs could be used for comparison and validation studies in many different ways. ${ }^{5}$

We envisioned that incorporation of triazole functionality into the backbone of diarylprolinol may serve as a proline surrogate potentially useful for organocatalysis. ${ }^{6}$ Previously, the sequential synthesis of highly hindered $\beta$-amino triazoles bearing a gem-diaryl group has been accomplished from 1,1diaryl-2-aminoethanols in part employing the copper catalysis. ${ }^{7}$ Attention next turned to the construction of pairwise surrogates. During the investigation, we found an exclusive formation of 1,4disubstituted triazoles from ruthenium-catalyzed cycloaddition particularly between sterically hindered azides and terminal alkynes even under the $\mathrm{Cp}{ }^{*} \mathrm{RuCl}\left(\mathrm{PPh}_{3}\right)_{2}$ catalyst. Herein we wish to discuss the effect of steric factors on the regioselectivity of the RuAAC using azide partners embedded in the bulky group.

The first choice was $\mathrm{Cp} * \mathrm{RuCl}\left(\mathrm{PPh}_{3}\right)_{2}$ as it has been widely used for the construction of 1,5-disubstituted triazoles. However, surprisingly the product $\mathbf{2 a}$ from the reaction of $\mathbf{1 a}$ with phenylacetylene was completely matched with the triazole from CuAAC. The result is in contrast with the reported regioselectivity of the RuAAC of terminal alkynes with $\mathrm{Cp} * \mathrm{RuCl}\left(\mathrm{PPh}_{3}\right)_{2}$ that show the preference for forming the 1,5-regioisomers. It seems we needed to clarify an ambiguity of a possible coordination of the secondary amine to a metal centre that may cause a change in the regioselectivity. Hence, the reaction between $N$-tosyl-protected $\mathbf{1 b}$ and ethyl propiolate was subjected and X-ray crystal structure of $\mathbf{2 b}$ clearly revealed the 1,4-rigioisomer as shown in Scheme 2. $\dagger$ Even both reactions were not completed in toluene at given times, the reverse regioselectivity is quite unusual behaviour, as seen previously in the ruthenium complexes containing the $\mathrm{Cp}^{*}$ ligand.

We next questioned that the observed selectivity is general when employing different ruthenium complexes, which have been addressed on the regioselective formation of the triazoles in the literature. The $\mathrm{Cp}^{*}$-containing ruthenium catalysts such as $\mathrm{Cp}{ }^{*} \mathrm{RuCl}\left(\mathrm{PPh}_{3}\right)_{2},{ }^{4 a} \mathrm{Cp}{ }^{*} \mathrm{RuCl}(\mathrm{COD}),{ }^{4 a, b}$ and $\left[\mathrm{Cp}^{*} \mathrm{RuCl}\right]_{4}$ (ref. $4 c$ and $d$ ) give 1,5-disubstituted triazoles with high regioselectivity, 


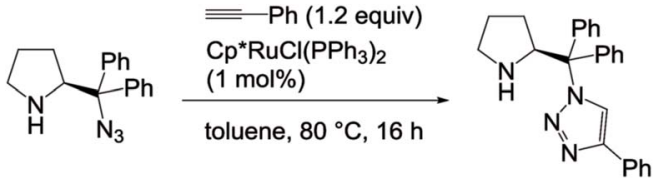

1a

2a $(16 \%)$
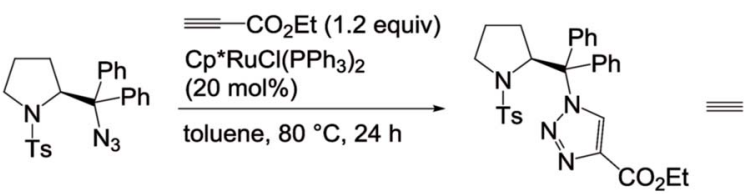

1b

$2 b(21 \%)$



Scheme 2 Observation of reverse selectivity under the $\mathrm{Cp} * \mathrm{RuCl}\left(\mathrm{PPh}_{3}\right)_{2}$ catalyst.

whereas $\mathrm{CpRuCl}\left(\mathrm{PPh}_{3}\right)_{2}$ (ref. $\left.4 b\right)$ containing a cyclopentadienyl ligand (Cp) shows marginal regioselectivity and catalytic activity towards 1,5-regioisomers. On the other hand, $\mathrm{Cp} * / \mathrm{Cp}$-lacking $\mathrm{RuH}_{2}(\mathrm{CO})\left(\mathrm{PPh}_{3}\right)_{3}$ (ref. $8 a$ ) and $\mathrm{RuH}\left(\eta^{2}-\mathrm{BH}_{4}\right)(\mathrm{CO})(\mathrm{PCy})_{2}$ (ref. $\left.8 b\right)$ afford 1,4-regioisomers selectively. It seems clear that the $\mathrm{Cp}^{*}$ ligand serves as the key element responsible for the high 1,5selectivity in the ruthenium catalysis.

Examinations were thus undertaken with different $\mathrm{Cp}^{*}$-containing catalysts, where DMF was the best choice and the reactions were completed within $20 \mathrm{~h}$. The tertiary azide proved to be a relatively poor substrate quite possibly due to the steric hindrance imposed by the two phenyl groups, however, the RuAAC reactions were equally effective for the generation of 1,4regioisomer as the sole product (Table 1, entries 1-3). The catalysts $\mathrm{RuH}_{2}(\mathrm{CO})\left(\mathrm{PPh}_{3}\right)_{3}$ and $\mathrm{Tp}\left(\mathrm{PPh}_{3}\right)\left(\mathrm{EtNH}_{2}\right) \mathrm{RuN}_{3}(\mathrm{Tp}=$ $\mathrm{HB}(\mathrm{pz})_{3}, \mathrm{pz}=$ pyrazolyl $^{9}$ also produced the 1,4-disubstituted

Table 1 Screening of ruthenium catalysts by the reaction of $1 \mathrm{a}$ with phenylacetylene $^{a}$

\begin{tabular}{|c|c|c|c|c|}
\hline Entry & Ru catalyst & $\begin{array}{l}\text { Equiv. of } \\
\text { alkyne }\end{array}$ & $\begin{array}{l}\text { Reaction } \\
\text { time }^{b}(\mathrm{~h})\end{array}$ & $\begin{array}{l}\text { Yield } \\
\text { of } 2 \mathbf{a}^{c}(\%)\end{array}$ \\
\hline 1 & $\mathrm{Cp} * \operatorname{RuCl}\left(\mathrm{PPh}_{3}\right)_{2}$ & 2 & 16 & 46 \\
\hline 2 & $\mathrm{Cp} * \operatorname{RuCl}(\mathrm{COD})$ & 2 & 20 & 41 \\
\hline 3 & {$[\mathrm{Cp} * \mathrm{RuCl}]_{4}$} & 3 & 16 & 47 \\
\hline 4 & $\mathrm{RuH}_{2}(\mathrm{CO})\left(\mathrm{PPh}_{3}\right)_{3}$ & 3 & 20 & 37 \\
\hline 5 & $\mathrm{Tp}\left(\mathrm{PPh}_{3}\right)\left(\mathrm{EtNH}_{2}\right) \mathrm{RuN}_{3}$ & 2 & 24 & 23 \\
\hline $6^{d}$ & - & 3 & 72 & $-^{e}$ \\
\hline
\end{tabular}

${ }^{a}$ Unless otherwise indicated, reaction conditions are as follows: 1a (1 mmol), Ru catalyst ( $1 \mathrm{~mol} \%)$, phenylacetylene (2-3 equiv.), DMF, $150{ }^{\circ} \mathrm{C}$. ${ }^{b}$ At a given time, 1a was completely consumed or decomposed. ${ }^{c}$ No 1,5-regioisomer observed. ${ }^{d}$ Thermal Huisgen reaction performed without the catalyst. ${ }^{e}$ No reaction observed. triazole but with slightly lower yield than the $\mathrm{Cp}^{*}$-containing catalysts (entries 4 and 5). Regardless of the ruthenium catalysts tested, the reactions exhibited 1,4-selectivity exclusively. Due to the unique outcomes, we then needed to measure the thermal contribution to the reaction and the result suggests that there is no contribution from the thermal to the observed regioselectivity (entry 6). By the way, supplementary attempts to obtain 1,5isomers were not fruitful, as applying alternative protocols based on the generation of magnesium acetylide ${ }^{10 a}$ or the presence of catalytic tetramethylammonium hydroxide ${ }^{10 b}$ respectively.

We next turned our attention to other substrates as shown in Table 2, which used previously in the CuAAC affording the exclusive formation of 1,4-triazoles. The RuAAC reactions of 2,2-diaryl-2azidoamines derived from valine, phenylglycine, and phenylalanine reconfirmed the exclusive formation of 1,4-regioisomers as revealed by ${ }^{1} \mathrm{H}$ and ${ }^{13} \mathrm{C}$ NMR analysis $(2 \mathbf{c}-2 \mathbf{e})$. On the other hand, interestingly, internal alkynes such as 1-phenyl-1-propyne ${ }^{11}$ and 3phenyl-2-propyn-1-ol ${ }^{4 b}$ with 1a were totally inactive in the RuAAC. Over again, the azides lacking the amino group also produced the single regioisomer (2f and $\mathbf{2 g}$ ). Accordingly, we could rule out the possible coordination of the amine moiety with metal centre which may alter the catalytic activity.

To understand influence of the steric demand in the regioselectivity, 2-(azidomethyl)pyrrolidine $\mathbf{3 a}$ was chosen and subjected to the cycloadditions under the copper and ruthenium catalysts, respectively, as shown in Scheme 3. Regioselective formation of isomeric triazoles could be viable, as the CuAAC of 3a produced 1,4-regioisomer $\mathbf{4 a}^{6 \boldsymbol{d}}$ and the corresponding 1,5 -isomer $\mathbf{4 b}$ was obtained by the RuAAC under the catalyst $\mathrm{Cp} * \mathrm{RuCl}\left(\mathrm{PPh}_{3}\right)_{2}$. Two

Table 2 Regiospecific formation of 1,4-disubstituted triazole isomers via RuAAC

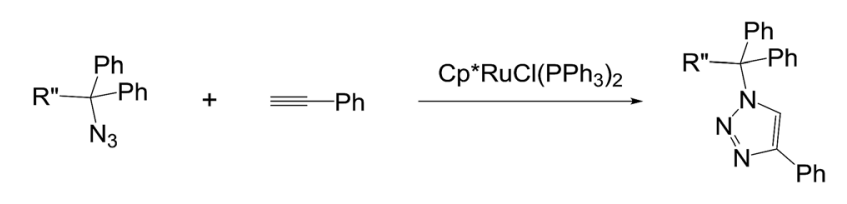

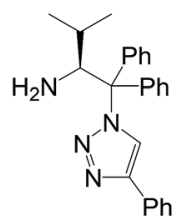

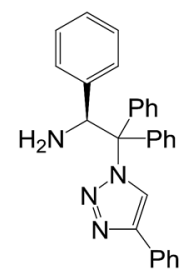

$2 \mathrm{c}(25 \%)$

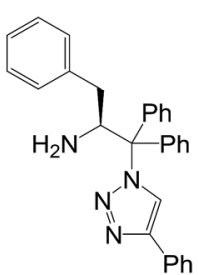

$2 \mathrm{e}(32 \%)$

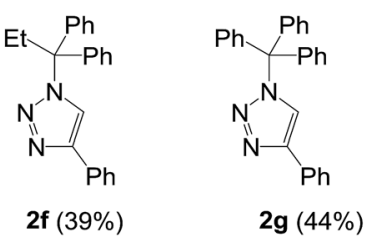

${ }^{a}$ The reaction conditions are as follows: azide (1 $\left.\mathrm{mmol}\right)$, phenylacetylene (2.5 equiv.), $\mathrm{Cp} * \operatorname{RuCl}\left(\mathrm{PPh}_{3}\right)_{2}(1 \mathrm{~mol} \%), \mathrm{DMF}, 150{ }^{\circ} \mathrm{C}$, $20 \mathrm{~h}$. 


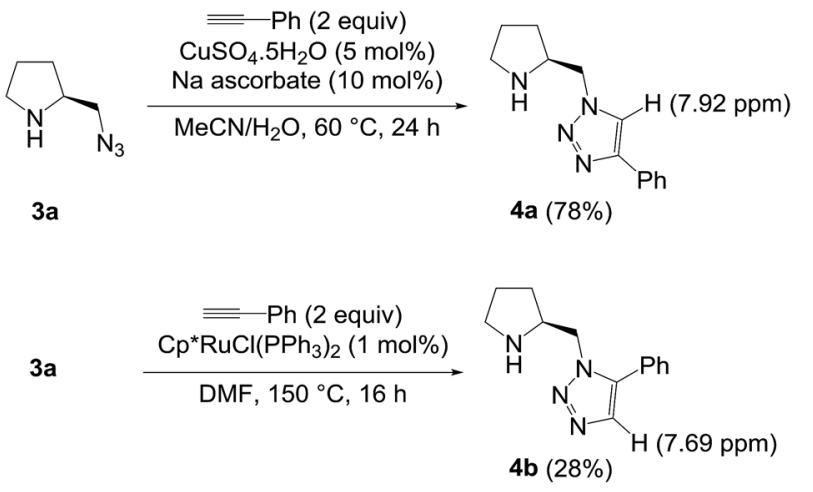

Scheme 3 Regioselective formation of isomeric triazoles by CuAAC and RuAAC of $3 a$.

regioisomers are distinguished by the comparison to NMR spectroscopy. The contrasting results from $\mathbf{1 a}$ and $\mathbf{3 a}$ reveal the substantial influence on the regioselectivity of the RuAAC, and thus suggest that the preference could be overridden by steric demands imposed by bulky groups on the azide partners.

Subsequently, we selected the substrates representing a structural intermediacy in bulkiness with the intention of deciphering the relationship between steric factors and selectivity by the determination of product population. Thus, three different types of 1,3-dipolar cycloaddition were undertaken separately (Table 3). All CuAAC reactions of sterically hindered azides solely

Table 3 Dependency on the bulkiness of azides in the 1,3-dipolar cycloaddition

$$
\text { Triazole (yield, ratio) }
$$

\begin{tabular}{|c|c|c|c|}
\hline Azide & By CuAAC $^{a}$ & By RuAAC ${ }^{b}$ & By heating ${ }^{c, d}$ \\
\hline
\end{tabular}

$\mathbf{5 A}(82 \%) \quad \mathbf{5 B}(52 \%) \quad-^{e}$

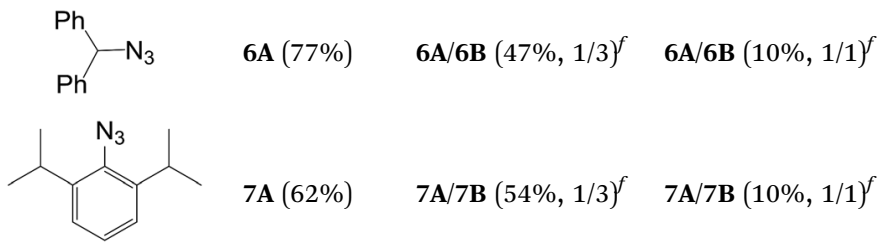

\footnotetext{
${ }^{a}$ Reaction conditions: azide ( $\left.1 \mathrm{mmol}\right)$, phenylacetylene (1.2 equiv.), $\mathrm{CuSO}_{4} \cdot 5 \mathrm{H}_{2} \mathrm{O}(10 \mathrm{~mol} \%), \mathrm{Na}$ ascorbate $(20 \mathrm{~mol} \%), \mathrm{MeCN} / \mathrm{H}_{2} \mathrm{O}=1 / 1(5$ $\mathrm{mL}), \mathrm{rt}, 16 \mathrm{~h} .{ }^{b}$ Azide (1 $\left.\mathrm{mmol}\right)$, phenylacetylene (2.5 equiv.), $\mathrm{Cp} * \operatorname{RuCl}\left(\mathrm{PPh}_{3}\right)_{2}(1 \mathrm{~mol} \%)$, DMF $(5 \mathrm{~mL}), 150{ }^{\circ} \mathrm{C}, 16$ h. ${ }^{c}$ Azide $(1$ mmol), phenylacetylene (2.5 equiv.), DMF $(5 \mathrm{~mL}), 150{ }^{\circ} \mathrm{C}, 72 \mathrm{~h}$. ${ }^{d}$ Reaction not completed after $72 \mathrm{~h}$. ${ }^{e}$ Reaction not performed.

${ }^{f}$ Isolated as mixtures and ratio based on NMR.
}
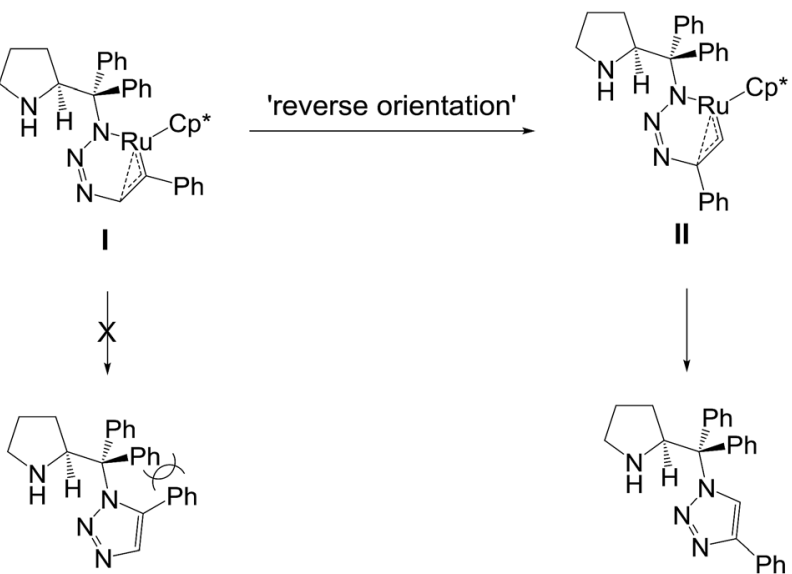

2a' (not formed)

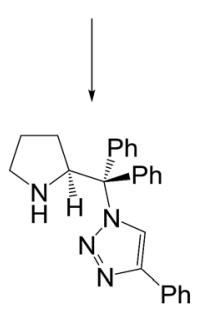

2a

Scheme 4 Stereochemical analysis of possible ruthenacylclic intermediates.

afforded 1,4-triazoles in good yields. In contrary, when benzhydryl azide and 2,6-diisopropyl-1-azidobenzene were treated with the ruthenium catalyst, arguably, 1,4-regioisomers appeared in both cases. For the same substrates, the thermal reactions gave the regioisomeric mixtures at the ratio of $1 / 1$, but only in very low yield. In particular to adamantyl azide, the RuAAC solely gave 1,5regioisomers as the azide group can be freely exposed to the metal centre presumably due to the configurationally constrained tricyclic backbone. It is now obvious that steric effect plays an important role in the regioselectivity in the RuAAC. ${ }^{12}$

The RuAAC appears to proceed via oxidative coupling of the azide and the alkyne to give a ruthenacycle which exerts a complete control over regioselectivity. However, the formation of the ruthenacycle I might be hampered considerably by the stereo-demanding nature of steric bulkiness within such a highly strained intermediacy and this may explain the observed 1,5-regioisomer. Furthermore, an attempted product $2 \mathbf{a}^{\prime}$ would be extremely destabilised by the allylic strain exerting between two substituents, as illustrated in scheme 4. The mechanistic considerations for this unprecedented observation need much more studies, but we propose that spatial crowding can alter the metal binding mode and eventually induce a reverse orientation to the incoming alkyne, a CuAAC-like ruthenacycle such as II. Likewise, inertness to internal alkyne also supports this proposal.t.

† Many attempts at intercepting a possible Ru-triazole intermediate such as III were unsuccessful; for the trapping of Cu-triazole intermediates: see, (a) W. Wang, F. Wei, Y. Ma, C.-H. Tung and Z. Xu, Org. Lett., 2016, 18, 4158; (b) Y.-M. Wu, J. Deng, Y. Li and Q.-Y. Chen, Synthesis, 2005, 1314; (c) X. Zhang, R. P. Hsung and H. Li, Chem. Commun., 2007, 2420.

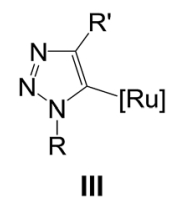


In summary, we observed the unprecedented formation of 1,4-disubstituted-1,2,3-triazoles from the reaction of 2,2-diaryl2 -azidoamines and terminal alkynes in the presence of ruthenium catalysts bearing $\mathrm{Cp}^{*}$ ligand. The reversal in regioselectivity is presumably due to the steric congestion arose from the geminal diaryl groups of the azide, as evidenced from the control experiment with 2-(azidomethyl)pyrrolidine revealing the usual selectivity with RuAAC. The contrasting results suggest that the steric demands imposed by the bulky groups of the azides could annul the preference and influence the regioselectivity of RuAAC substantially. We thus surmise that the formation of the ruthenacycle allowing the 1,5-regioselectivity might be hampered considerably by the stereo-demanding nature within such a highly strained intermediacy causing the reverse orientation of the alkyne leading to the 1,4-regioisomer. Furthermore, RuAAc of the bulky azides was inactive to internal alkynes and this suggests that the mechanism is more likely to resemble CuAAC pathway. In addition, the RuAAC reactions of azides with intermediate bulkiness gave the mixtures of 1,4- and 1,5-regioisomers providing the additional support to this hypothesis.

\section{Acknowledgements}

This work was supported by the Creative Challenge Project (KK1607-C03) of the Korea Research Institute of Chemical Technology, Taejon, Korea.

\section{Notes and references}

1 R. Huisgen, Angew. Chem., Int. Ed., 1963, 2, 565.

2 (a) V. V. Rostovtsev, L. G. Green, V. V. Fokin and K. B. Sharpless, Angew. Chem., Int. Ed., 2002, 41, 2596; (b) C. W. Tornøe, C. Christensen and M. Meldal, J. Org. Chem., 2002, 67, 3057.

3 (a) H. C. Kolb and K. B. Sharpless, Drug Discovery Today, 2003, 8, 1128; (b) K. Majumdar and K. Ray, Synthesis, 2011, 3767; (c) P. Wu and V. V. Fokin, Aldrichimica Acta, 2007, 40, 7; (d) J. E. Moses and A. D. Moorhouse, Chem. Soc. Rev., 2007, 36, 1249; (e) P. Thirumurugan, D. Matosiuk and K. Jozwiak, Chem. Rev., 2013, 113, 4905.

4 (a) L. Zhang, X. Chen, P. Xue, H. H. Y. Sun, I. D. Williams, K. B. Sharpless, V. V. Fokin and G. Jia, J. Am. Chem. Soc., 2005, 127, 15998; (b) B. C. Boren, S. Narayan, L. K. Rasmussen, L. Zhang, H. Zhao, Z. Lin, G. Jia and V. V. Fokin, J. Am. Chem. Soc., 2008, 130, 8923; (c)
L. K. Rasmussen, B. C. Boren and V. V. Fokin, Org. Lett., 2007, 9, 5337; (d) J. Zhang, J. Kemmink, D. T. S. Rijkersa and R. M. J. Liskamp, Chem. Commun., 2013, 49, 4498; (e) M. Lamberti, G. C. Fortman, A. Poater, J. Broggi, A. M. Z. Slawin, L. Cavallo and S. P. Nolan, Organometallics, 2012, 31, 756.

5 (a) U. Pradere, V. Roy, T. R. McBrayer, R. F. Schinazi and L. A. Agrofoglio, Tetrahedron, 2008, 64, 9044; (b) J. M. Kwak, J. S. Moon, S. Seo, J. I. Choi, V. Sampath, H.-Y. Lee and H. Y. Koh, Bull. Korean Chem. Soc., 2014, 35, 3675; (c) H. Nulwala, K. Takizawa, A. Odukale, A. Khan, R. J. Thibault, B. R. Taft, B. H. Lipshutz and C. J. Hawker, Macromolecules, 2009, 42, 6068.

6 (a) K. R. Knudsen, C. E. T. Mitchell and S. V. Ley, Chem. Commun., 2006, 1, 66; (b) T. Ishii, S. Fujioka, Y. Sekiguchi and H. Kotsuki, J. Am. Chem. Soc., 2004, 126, 9558; (c) S. Luo, X. Mi, L. Zhang, S. Liu, H. Xu and J.-P. Cheng, Angew. Chem., Int. Ed., 2006, 45, 3093; (d) S. Luo, H. Xu, X. Mi, J. Li, X. Zheng and J.-P. Cheng, J. Org. Chem., 2006, 71, 9244.

7 (a) H. Roy, A. Pitchaiah, M. Kim, I. T. Hwang and K. I. Lee, RSC Adv., 2013, 3, 3526; (b) V. S. Sadu, H. Roy, A. Pitchaiah, I. T. Hwang and K. I. Lee, Bull. Korean Chem. Soc., 2014, 35, 1605.

8 (a) P. N. Liu, L. Zhang, C. Shi and G. Jia, J. Org. Chem., 2012, 77, 5844; (b) P. N. Liu, J. Li, H. S. Su, K. D. Ju, L. Zhang, C. Shi, H. H. Y. Sung, I. D. Williams, V. V. Fokin, Z. Lin and G. Jia, Organometallics, 2012, 31, 4904.

9 Tp-containing $\mathrm{Ru}$ catalyst is also known to give 1,5regioselectivity: see, T.-H. Wang, F.-L. Wu, G.-R. Chiang, S.-T. He and Y.-H. Lo, J. Organomet. Chem., 2014, 774, 57.

10 (a) A. Krasiński, V. V. Fokin and K. B. Sharpless, Org. Lett., 2004, 6, 1237; (b) S. W. Kwok, J. R. Fotsing, R. J. Fraser, V. O. Rodionov and V. V. Fokin, Org. Lett., 2010, 12, 4217.

11 M. M. Majireck and S. M. Weinreb, J. Org. Chem., 2006, 71, 8680 .

12 Selected papers for steric effects on reactivity and selectivity: see, (a) V. P. Ananikov, R. Szilagyi, K. Morokuma and D. G. Musaev, Organometallics, 2005, 24, 1938; (b) S. Yoshida, A. Shiraiah, K. Kanno, T. Matsushita, K. Johmoto, H. Uekusa and T. Hosoya, Sci. Rep., 2011, 1, 82; (c) L. Wang and J. Xiao, Org. Chem. Front., 2016, 3, 635; (d) D. W. Crandell, S. Mazumdar, P. A. Evans and M.-H. Baik, Chem. Sci., 2015, 6, 6896. 